\title{
As práticas educativas e o pedagogo hospitalar ${ }^{1}$
}

\author{
Araci Asinelli-Luz ${ }^{2}$ \\ Tatiane Delurdes de Lima-Berton ${ }^{3}$ \\ Michelle Popenga Geraim Monteiro ${ }^{4}$
}

\begin{abstract}
RESUMO
O resgate do processo de humanização dos hospitais vem ao encontro da pedagogia hospitalar que alicerça e dá continuidade aos estudos daqueles que necessitam de atendimento escolar e que por alguma razão encontram-se em condições de enfermidades, que estejam impedidos temporariamente de retomar a normalidade da sua vida social, familiar e escolar. Nesse sentido, o presente estudo busca compreender as práticas educativas do educador/pedagogo hospitalar para promoção da Educação em ambientes hospitalares. Para isso, utilizou-se de uma pesquisa qualitativa, de cunho teórico, para a discussão sobre possíveis práticas educativas com base na Pedagogia Hospitalar. Pensa-se que tais práticas educativas no ambiente hospitalar podem favorecer a inclusão social, melhoria clínica de crianças e adolescentes e retomada dos estudos que foram interrompidos na escola, bem como enfatizar a produção de pesquisas na área.
\end{abstract}

PALAVRAS-CHAVE: Educação. Humanização. Pedagogia hospitalar.

\section{Educationl practices and Hospital Pedagogue}

\section{ABSTRACT}

The rescue of the humanization process of hospitals is in line with the hospital pedagogy that underpins and continues the studies of those who

\footnotetext{
${ }^{1}$ O presente trabalho foi realizado com apoio da Coordenação de Aperfeiçoamento de Pessoal de Nível Superior Brasil (CAPES) - Código de Financiamento 001.

${ }^{2}$ Doutora em Educação. Universidade Federal do Paraná, Curitiba, Paraná, Brasil. Orcid: https://orcid.org/0000-00015880-0543. E-mail: araciasinelli@gmail.com.

${ }^{3}$ Doutoranda em Educação. Universidade Federal do Paraná, Curitiba, Paraná, Brasil. Orcid: https://orcid.org/00000001-6653-2593.E-mail: tati8lima@gmail.com.

${ }^{4}$ Doutoranda em Educação. Universidade Federal do Paraná, Curitiba, Paraná, Brasil. Orcid: https://orcid.org/00000003-3058-8987. E-mail: mizinhadobru@yahoo.com.br.
} 
need school attendance and who for some reason are in conditions of illness, who are temporarily prevented from resuming their normality. social, family and school life. In this sense, the present study seeks to understand the educational practices of the hospital educator / pedagogue to promote Education in hospital environments. For this, a qualitative research, of a theoretical nature, was used to discuss possible educational practices based on Hospital Pedagogy. It is thought that such educational practices in the hospital environment may favor social inclusion, clinical improvement of children and adolescents and resumption of studies that were interrupted at school, as well as emphasizing the production of research in the area.

KEYWORDS: Education. Humanization. Hospital pedagogy.

\section{Prácticas educativas y Pedagogo Hospitalario}

\section{RESUMEN}

The rescue of the humanization process of hospitals is in line with the hospital pedagogy that underpins and continues the studies of those who need school attendance and who for some reason are in conditions of illness, who are temporarily prevented from resuming their normality. social, family and school life. In this sense, the present study seeks to understand the educational practices of the hospital educator / pedagogue to promote Education in hospital environments. For this, a qualitative research, of a theoretical nature, was used to discuss possible educational practices based on Hospital Pedagogy. It is thought that such educational practices in the hospital environment may favor social inclusion, clinical improvement of children and adolescents and resumption of studies that were interrupted at school, as well as emphasizing the production of research in the area.

PALABRAS CLAVE: Educacion. Humanización. Hospital de pedagogia.

$$
* * *
$$




\section{Introdução}

A Educação, como área de conhecimento, é promotora de transformações sociais, em busca de uma sociedade mais justa e igualitária. Com as demandas advindas de vulnerabilidades e riscos sociais, bem como problemáticas de saúde e de demandas sociais, surgem diversas alterações no ambiente escolar. Um dos fatores que podem impossibilitar uma criança, adolescente de realizar seus estudos é a sua saúde. Quando se interrompe sua ida à escola e, o educando passa a obter atendimentos hospitalares longos, seja por meio da internação do domiciliar, a Pedagogia Hospitalar promove a garantia do direito à Saúde e Educação juntas.

Desse modo, com o passar dos anos e, considerando as demandas que surgiram da sociedade, o Curso de Pedagogia precisou de modificações, transformações. Com a grande demanda de crianças, adolescentes e jovens hospitalizados, houve a necessidade de elaborar projetos para suprir a demanda escolar dentro dos centros hospitalares. Nesse âmbito, a Pedagogia Hospitalar é uma área de atuação dos profissionais da educação, que visam proporcionar a crianças e adolescentes hospitalizados acesso ao ensino, oferencdo a inserção e a re-inserção desses indivíduos no contexto escolar.

Em âmbito normativo, as práticas pedagógicas e educativas que são elaboradas para crianças/adolescentes/jovens são reconhecidas pela modalidade de Educação Especial, em que essa modalidade regulamenta as práticas educacionais (BRASIL, 1996). De acordo com a Resolução CNE/CP $\mathrm{N}^{\mathrm{o}}$ 1, de 15 de Maio de 2006, as atividades docentes deverão envolver participação na gestão e organização de sistemas e instituições de ensino, englobando o planejamento, execução, coordenação, acompanhamento e avaliação de tarefas próprias do setor da Educação; o planejamento, execução, coordenação, acompanhamento e avaliação de projetos e experiências educativas não-escolares, bem como a produção e difusão do conhecimento científico-tecnológico do campo educacional, em contextos escolares e nãoescolares. Com isso, a Pedagogia Hospitalar vem abrindo espaços de estudo e 
reflexões aos educadores e pedagogos que possuem a iniciativa de trabalhar com as diferentes clientelas fora do ambiente educacional (BRASIL, 2006).

A Declaração Universal dos Direitos da Criança apresenta essa preocupação com a escolarização hospitalar desde 1959, bem como outros parâmetros normativos como a Constituição Federal Brasileira de 1988, o Estatuto da Criança e do Adolescente (1990), o Conselho Nacional dos Direitos da Criança e do Adolescente (1991) e o Conselho Nacional de Educação. A Lei de Diretrizes e Bases da Educação (Lei n ${ }^{\circ} 9394$ de 20 de dezembro de 1996), em seu artigo $4^{\circ} \mathrm{A}$, garante a educação escolar gratuita, bem como o atendimento educacional durante o período de internação ao educando inserido na Educação Básica (para o tratamento de saúde em regime hospitalar ou domiciliar).

Por meio do conhecimento dessas leis, pode-se entender que ao Pedagogo Hospitalar caberá o efetivo envolvimento com o doente para modificar o ambiente hospitalar, criando programas de intervenção adaptados para o contínuo desenvolvimento da criança hospitalizada em parceria com a escola que a criança estuda. A prática educacional no hospital, além de ser possível, é extremamente importante para amenizar o processo doloroso que é rotina de um enfermo (SILVA; CARDOSO; SANTOS, 2012, p. 48).

Pensar na legislação e na trajetória da educação brasileira é também observar que até pouco tempo a ação do pedagogo limitava-se ao espaço escolar e, com o passar dos anos, surgiu a necessidade de novas atribuições e espaços de atuação - área social, empresarial e hospitalar. A prática do pedagogo hospitalar tornou-se necessária para que crianças/adolescente/jovens possam ser atendidos no ambiente hospitalar e ou domiciliar. Desse modo, a Pedagogia Hospitalar é um processo alternativo de Educação, de forma continuada, que possibilita que crianças, adolescentes e adultos hospitalizados recebam o ensino escolar, para que se possam promover oportunidades de relação social, assim como ao não fracasso e desistência escolar. Inseridos em um ambiente acolhedor e humanizado, o pedagogo hospitalar poderá ser a 
ponte entre o educando e o meio exterior (incentivando as relações sociais e reforçando os laços familiares) (MATOS, 1998).

Trata-se de uma Pedagogia do presente que envolve saberes da e para a vida. Visa o atendimento global do educando hospitalizado, possibilitando que a equipe hospitalar, a família e a escola trabalhem juntos, interagindo no intuito de acelerar o seu processo de recuperação e de aproximação com a realidade escolar: "o professor da escola hospitalar é, antes de tudo, um mediador das interações da criança com o ambiente hospitalar" (FONSECA, 2003, p. 25).

O Pedagogo - atuando como mediador, assim como o educador - ajuda na socialização da criança com as demais pessoas do ambiente, sejam essas outras crianças hospitalizadas, sejam profissionais da equipe de trabalho do hospital e até mesmo do âmbito da escola. Destacam que o trabalho do Pedagogo possibilita que o dia a dia do educando se torne menos desgastante e sua recuperação seja mais rápida (REIS; COSTA, 2015; MATOS; MUGIATTI, 2009).

Ademais, os professores e Pedagogos hospitalares para que consigam exercer seu papel e para que obtenham melhores resultados em seu trabalho junto com os educandos hospitalizados, necessitam de contínua formação e especialização, para que esse atendimento individualizado seja respeitado e adaptado de acordo com cada caso. É necessário conhecimentos teóricos e práticos em relação ao cotidiano do hospitalizado, em que o profissional precisa conhecer as especificidades do paciente, de sua doença, para que a adaptação no ambiente hospitalar ocorra com maior autonomia, transmitindo segurança para a criança \adolescente e seus familiares (REIS; COSTA, 2015; MATOS; MUGIATTI, 2009).

Cursos de formação de professores que não alcancem essa amplitude de compreensão, dificilmente conseguirão contribuir na formação de futuros docentes comprometidos com a transformação social, e sim, limitar-se-á formá-los sob o viés da reprodução-manutenção da sociedade tal qual se encontra (RIBEIRO, 2016, p. 530). 
Devido a importância da escolarização hospitalar, a atuação do pedagogo no que diz respeito ao atendimento de crianças/ adolescentes/jovens pode se tornar abrangente e de suma importância, em que uma de suas atribuições envolve a mediação entre a equipe médica, família e escola.

[...] há muito para um hospital aprender com a educação escolar para transpor à prática clínica na instituição de relações organizadas para a criança, aprendendo a operar com o reconhecimento da situação social particular, ligada, ao mesmo tempo, à condição de criança e a um ambiente social determinado, preservando a espontaneidade e a originalidade da criança (CECCIM,1999, p. 32).

Ceccim (1999) apresenta que a educação escolar pode e deve estar presente em todos os ambientes, principalmente nos hospitais e que se deve respeitar as condições e o momento que a criança/adolescente/jovem está vivendo. O papel do pedagogo hospitalar no meio educacional é de extrema importância, pois, tem a finalidade de acompanhar, planejar, socializar e, principalmente, mediar todas as questões que dizem respeito a criança/adolescente/jovem no âmbito hospitalar, familiar e escolar (MATOS, 1998).

Quando o pedagogo realiza a ponte entre tais segmentos, ele tem a oportunidade de proporcionar a melhoria da qualidade no ensino, no acolhimento desse aluno, oportunizando que, mesmo estando longe do seu ambiente escolar, ainda se sinta participante dele (MATOS, 1998). Esse Pedagogo Hospitalar, o educador que no espaço do hospital atua, advém da Educação em espaços não escolares, mesmo tratando-se do ensino da escola. Seu perfil é diferente, assim como do Pedagogo Empresarial ou Social, em que a atuação é com e para os sujeitos e a sua inclusão social. Com a compreensão das novas necessidades de promover a Educação em espaços não escolares, o educador no espaço do hospital também torna-se um profissional essencial.

O educador é um profissional que busca qualificação para atuar não somente na Educação Infantil, mas também em 
outros espaços que implicam diversos campos educativos, e essa atuação pode ser formal, não formal e informal. Sendo assim ele deixa de atuar só em questões escolares (formais), conquistando um espaço (extra-escolar) bem mais amplo (PARREIRA; JOSÉ FILHO, 2010, p. 252).

Conhecer o educador é também conhecer o seu espaço de atuação. Na Pedagogia Hospitalar, o educador e pedagogo contribuem para uma nova maneira de enfrentar os desafios clínicos, aproximando o contexto externo do educando ao que está vivendo. Pode-se contribuir não apenas para o tratamento ou cura de doenças, mas, servir como um grande mediador entre o educando e a escola. O objetivo é o de oferecer aos educandos hospitalizados ou em tratamento de longo prazo, o cumprimento de seus direitos, tais como a Saúde e a Educação, valorizando-a como ser humano e como participante da sociedade. Nessa perspectiva, a Pedagogia Hospitalar vem a desenvolver projetos e ações educativas junto a pedagogos, psicólogos, assistentes sociais, a família e a toda equipe técnica do hospital, com o intuito de complementar de forma coerente e participativa a aproximação do paciente com a educação (MATOS; MUGIATTI, 2009).

Além de a Pedagogia Hospitalar promover o bem estar ao paciente, também promove ao educador. Segundo Dutra (2009, p.16), "além dos benefícios para o atendimento de crianças e adolescentes hospitalizados a proposta de inserção do Pedagogo nos Hospitais abriu novas portas para o campo de atuação profissional." Assim, o pedagogo e os educadores possuem a oportunidade de vivenciar novos ambientes que não sejam apenas o da escola, que não desenvolvam apenas um trabalho voltado ao ensino dentro de sala de aula.

Nesta perspectiva, o educador e o pedagogo que saem do ambiente escolar e vão até o espaço hospitalar, tem a oportunidade de vivenciar novas expectativas e experiências, oferecendo seu trabalho de forma mais dinâmica e lúdica e, aprendendo a conviver com outros tipos de profissionais diferentes de 
sua área de atuação, construindo então, novas alternativas de atuação dentro do hospital, novas visões de mundo e novos métodos de interação grupal.

Esse tema traz à tona algumas especificidades das quais não se observa nas escolas e, até mesmo na academia (nos cursos de formação inicial e continuada). Tem-se como outro pressuposto que ainda há dificuldades do educador e do pedagogo hospitalar compreenderem suas funções e, principalmente, de reconhecerem sua identidade profissional. E esse tema envolvendo a Pedagogia Hospitalar e as práticas do educador e do pedagogo nessa área reforçam a necessidade de pesquisas que ampliem a discussão sobre o educando e o seu processo de tratamento hospitalar, bem como da relação do convívio com seus familiares, amigos e o ambiente escolar. Esse tema pode oportunizar outros estudos, pesquisas para a melhoria do atendimento nas classes hospitalares e sobre a função de mediador do educador e do pedagogo hospitalar.

Esse estudo torna-se importante para a sociedade porque se faz necessário que se tenha outro olhar para os educandos hospitalizados, que as pessoas envolvidas com esse processo participem mais, tanto a família, quando os profissionais do hospital e da escola. Que ocorra a sensibilização pela sociedade como um todo, pois, trata-se também de uma questão social. Pensando assim nas contribuições da Pedagogia Hospitalar para a promoção do ensino e da interação em espaços não escolares, sendo no hospital ou em atendimentos domiciliares de educandos que necessitam da ação da Saúde, o presente estudo possui como pergunta norteadora "quais práticas do educador/pedagogo escolar favorecem o ensino no contexto hospitalar?". Para responder a essa questão, têm-se como objetivo compreender as práticas educativas do educador/pedagogo hospitalar para promoção da Educação em ambientes hospitalares. Para isso, utilizou-se de uma pesquisa qualitativa, de cunho teórico, para a discussão sobre possíveis práticas educativas com base na Pedagogia Hospitalar. 


\section{Ações e posturas necessárias do educador e pedagogo hospitalar}

A Pedagogia Hospitalar possibilita a continuidade aos estudos dos educandos que estão em ambiente hospitalar ou em tratamento, com o objetivo de suprir as dificuldades de aprendizagem e oportunizar novos conhecimentos e informações. Desenvolvem-se ainda as necessidades cognitivas e psíquicas por meio do lúdico e de interação, realizando a ponte entre o sistema educacional e o de saúde (FONSECA, 2003).

Nessa perspectiva, compreende-se que nessa relação, "o principal efeito do encontro Educação Saúde para uma criança hospitalizada é a proteção do seu desenvolvimento e a proteção dos processos cognitivos e afetivos de construção dos aprendizados" (CECCIM; FONSECA, 1999, p.44). Ou seja, com a ligação entre Saúde e a Educação, há a complementaridade, o oferecimento de bem estar, disposição e qualidade de vida, enquanto a outra promove a oportunidade de entrar em contato com novas informações e conhecimentos, realizando a interação entre os indivíduos e consequentemente, abrindo novos espaços de discussão e reflexão crítica. É deixar de seguir comportamentos tradicionais, cartesianos e, repensar a prática para ações humanizadoras, estimulantes e sensibilizadoras. A condição da aprendizagem, em situação que difere do cotidiano de uma escola formal, requer um visão mais ampla do profissional, demandando práticas pedagógicas que superem os processos atuais.

A construção da prática pedagógica, para atuação em ambiente hospitalar, não pode esbarrar nas fronteiras do tradicional. As dificuldades, muitas vezes, persistem porque não se consegue ver nelas a oportunidade de uma atuação diferenciada, pois os valores e as percepções de condutas e ações estão ainda muito enraizados nas formações reducionistas. Essa prática, portanto, deve transpor as barreiras do tradicional e as dificuldades da visão cartesiana. A ação pedagógica, em ambiente e condições diferenciadas, como é o hospital, representa um universo de possibilidades para o desenvolvimento e ampliação da habilidade do pedagogo/educador. Desenvolver tais habilidades requer uma visão oposta à contemplada pelo redutivismo, ou seja, ela deve, sim, contemplar o todo (MATOS, 2010, p. 51). 
O educador, auxiliado pelo pedagogo, deve realizar "[...] a ponte entre o discurso oficial, que é o do médico e o discurso do senso comum, que é o dos pais ou responsáveis pela criança" (FONTES, 2005, p. 12). Assim, o seu papel além de mediador do ensino, deve ser o de auxiliar na relação entre os pais e os filhos, tranquilizando-os em relação ao quadro das doenças, e, possivelmente, contribuindo para o tratamento. Desse modo, além de atuar como mediador, ele amplia suas redes de relações dentro do ambiente hospitalar, promovendo não só benefícios às crianças e jovens hospitalizados, mas às suas famílias e à própria equipe técnica do hospital (FONTES, 2005).

Destaca-se que o educador, o pedagogo hospitalar precisa desenvolver algumas habilidades como a de adaptação nos espaços em que se encontra, tanto em relação à frequência dos educandos, quando das suas permanências no atendimento hospitalar, observar o espaço destinado à realização das atividades recreativas, lúdicas e pedagógicas; a disposição dos leitos; a rotina enfrentada; o levantamento da situação social das famílias dos pacientes e o conhecimento de cada educando, como por exemplo, o seu cotidiano e suas potencialidades (CECCIM; FONSECA, 1999; MATOS; MUGIATTI, 2009).

É preciso considerar a percepção de outras medidas humanizadoras, bem como as brinquedotecas, oficineiros, recreadores, voluntários, presenças dos familiares e da equipe técnica do hospital, com o objetivo de integrá-las às atividades realizadas em seu cotidiano (CECCIM; FONSECA, 1999; MATOS; MUGIATTI, 2009). O uso da sensibilidade em sugerir diferentes espaços do hospital para a realização das atividades criativas e funcionais também são importantes, visto que a exploração de outros locais possibilita a quebra da rotina, proporcionando aos educandos um ambiente repleto de dinâmicas e interações.

Os educadores devem ainda possuir a capacidade de adaptar as atividades de ensino aprendizagem, não interferindo nas práticas de cunho terapêutico e sim, auxiliar para que as desenvolvam. Deste modo, deve-se realizar um trabalho efetivo e cuidadoso as quais não devem confundir o atendimento educacional com o atendimento de Saúde. É preciso considerar 
que os profissionais assumem um papel de enriquecimento humano e educacional por meio das atividades e jogos lúdicos, a fim de proporcionar aos educandos o melhor caminho para a aprendizagem. Já a equipe médica em geral, deve prestar apoio em seu tratamento de saúde e em sua interação com o paciente, havendo um trabalho em equipe (MATOS; MUGIATTI, 2009).

Os educadores ainda devem ter a capacidade de propor materiais e maneiras alternativas de confecção de jogos e brincadeiras, para que, além do estímulo à própria produção dos educandos, faça-se a valorização das suas produções e a consciência do cuidado com os materiais diversos. Há ainda a sugestão de modos de acompanhamento escolar, contemplando-o na sua condição humana por meio de suas necessidades, sociais, físicas, psíquicas, de gênero, entre outras (BARROS, 2007).

Sabendo da situação em que os educandos s se encontram, Ceccim (1999) reforça que é necessário realizar atividades que estimulem a criatividade, a coordenação motora, o raciocínio lógico, a sensibilidade, e o estímulo de outros sentidos por meio de brincadeiras e jogos, a exibição de filmes, leituras e interpretações de história e ainda, atividades envolvendo a arte.

Barros (2007), nessa perspectiva, destaca que, depois de detectada as necessidades dos educandos, os educadores e/ou pedagogos devem motivar maneiras de pesquisas e de investigação dos conhecimentos, como por exemplo, o estudo dos casos dos pacientes e a qualidade das atividades, com o objetivo de constatar por meio das pesquisas a comparação de realidades similares e a qualidade dos projetos e das práticas pedagógicas. Com as leituras e as interpretações de histórias, estimula-se o acesso à informação escrita, individualmente ou em grupo, por meio de materiais como jornais, revistas, contos, histórias, gibis, biografias, poesias, entre outros recursos com o objetivo de distrair as crianças e os jovens e ainda, estimular a leitura e a escrita.

As atividades de artes podem contribuir no desenvolvimento de um trabalho criativo, que estimulem a livre expressão utilizando técnicas e materiais artísticos tais como o desenho, as pinturas, a construção de brinquedos com materiais recicláveis, os enfeites para festas 
comemorativas, as peças de teatro, entre outras atividades que podem auxiliar no protagonismo e na participação dos educandos, oportunizando assim, um espaço de muita descontração, alegria, interação e conhecimento. Além de práticas escritas, de leitura e de expressão corporal, pode-se fazer a inclusão digital, por meio da tecnologia, promovendo-se um espaço de interação, descontração, informação, trocas e o acréscimo de novos conhecimentos com o computador e a internet.

Tais experiências só podem ser possíveis com uma base teórica. O educador e o pedagogo hospitalar precisam de formação inicial (por meio do Curso de Pedagogia) e de formação continuada, para que possa atuar com as adversidades que o dia a dia hospitalar expressam. Além do conhecimento pedagógico, se faz necessário obter conhecimento sobre as patologias, causas, uma vez que estará imerso em um ambiente hospitalar, em parceria da equipe multidisciplinar (TAVARES, 2011).

O planejamento das ações e aulas necessitam de flexibilidade, pois, diferente da sala de aula, no hospital, as atividades e estudos propostos tem que ser no tempo do educando (TAVARES, 2011). A humanização é a chave na atuação do pedagogo e do educador hospitalar. Ações humanizadoras no atendimento exigem todo cuidado: os espaços precisam ser pensados, o atendimento às famílias se faz importante para que se sintam acolhidas e, saber que mesmo o educando estando doente, não terá perdas durante esse período de internamento. Nesse processo de humanização, integrando a Educação e Saúde,

Observa-se que a continuidade dos estudos, paralelamente ao internamento, traz maior vigor às forças vitais da criança (ou adolescente) hospitalizada, como estímulo motivacional, induzindo-o a ser tornar mais participante e produtivo, com vistas a uma efetiva recuperação. Tal fato, além de gerar uma integração a participação ativa que entusiasmam o escolar hospitalizado, pelo efetivo da continuidade da realidade externa, contribui, ainda de forma subconsciente, para o desencadeamento da vontade premente de necessidade de cura, ou seja, nasce uma predisposição que facilita sua cura e abrevia o seu retorno ao meio a que estava integrado (MATOS; MUGIATTI, 2009, p. 72). 
São profissionais que precisam de estruturação pedagógica que possam lhes oferecer base para estimular habilidades em si para exercer suas funções em ambientes integrados, onde as relações multidisciplinares necessitam ser fortalecidas. Tal condição requer um fazer e um agir que não devam estar vinculados a processos limitados, inflexíveis, deixando o educador livre para desenvolver seu trabalho de forma reflexiva e transformadora da realidade que envolve a criança/adolescente atendida no contexto hospitalar (SANTOS, 2011).

É fundamental que os profissionais que atuam como educadores e pedagogos hospitalares construam um perfil que vislumbre as necessidades dos educandos, realizando uma abordagem diferenciada e progressista. Não devem deixar de lado o tratamento que estão recebendo, tampouco deixá-lo desassistido do âmbito escolar. O papel principal do educador/pedagogo hospitalar é a de transformar essas duas realidades em que se está inserida. Sobre isto, Cardoso (1995, p. 48) destaca:

Educar significa utilizar práticas pedagógicas que desenvolvam simultaneamente razão, sensação, sentimento e intuição e que estimulem a integração intercultural e a visão planetária das coisas, em nome da paz e da unidade do mundo. Assim, a educação- além de transmitir e construir saber sistematizado- assume um sentido terapêutico ao despertar no educando uma nova consciência que transcende do eu individual para o eu transpessoal.

A visão do educador é integradora, com uma prática pedagógica que compreenda o âmbito total da Educação, que oportunize o desenvolvimento pleno do ser humano. Para uma Pedagogia Hospitalar, portanto, o educador "o que cria, que se ocupa da educação", segundo o Dicionário Larousse de cultura (LOVISOLO, 1992, p.386), deve ter também uma visão contextual, pois nela se faz realizar o verdadeiro sentido da interdisciplinaridade. Interagir em ambiente hospitalar de maneira multidisciplinar requer uma compreensão mais abrangente, aberta, para poder fluir o entendimento da realidade.

Pretende-se com isso que se desenvolva tanto em educandos como educadores a capacidade de 
transformação pessoal, aspecto fundamental para a transformação social. Pelo seu próprio caráter e experimental, o caminho e os resultados da holopráxis dificilmente podem ser traduzidos em palavras. Trata-se de um conhecimento incorporado pela sensibilidade e pela intuição e não simplesmente apreendido pelo intelecto (CARDOSO, 1995, p. 89).

É nesse contexto de multidisciplinaridade, de visualização do conceito integral de Educação, que se faz importante evidenciar práticas de mediação entre hospital e escola, de não restringir aos profissionais do hospital as informações em relação à criança, adolescente hospitalizada. Por isso, para a compreensão desse papel multisetorial, que há a necessidade de atuação de pedagogos e educadores que possam integrar suas ações pedagógicas com a interação com os demais profissionais em que atua, assim como à escola e as famílias (PARANÁ, 2010). Vale ressaltar a importância do alicerçar da formação acadêmica, para que em termos sociais, tenham a oportunidade de aprender a desenvolver práticas que vislumbram a adaptações de condições de aprendizagem que se instalam nos contextos hospitalares, que são diferenciados dos padrões de sala de aula.

A formação de professores, nesse viés, sempre se compromete com algum projeto societário. Projetos de conservação ou transformação social, e seja para um ou para o outro, a formação é ponto chave na construção desse processo e é elemento em constante disputa (RIBEIRO, 2016, p. 527).

$\mathrm{Na}$ construção da relação entre o pedagogo e o educador hospitalar, torna-se fundamental oferecer as mínimas condições de trabalho, tanto por parte das instituições de ensino, de formação do profissional, a fim de que os preparem pedagogicamente e emocionalmente. Tal demanda emerge de especificidades que em muitos casos necessita de atendimentos que concilie o horário em que o educando se sinta mais à vontade para estudar para aqueles em que esteja se recuperando de um procedimento invasivo ou, até mesmo, no período em que estará retornando à escola. E em relação a esses horários específicos, em que está disposto, o educador tenha sensibilidade, criatividade 
e atenção para subsidiar conteúdos de formas lúdicas, de modo que ele aprenda e se desenvolva cognitivamente de forma prazerosa (SANTOS, 2011).

Para os atendimento nos hospitais, o pedagogo e o educador hospitalar precisam estar em constante contato com a escola de referência, para que tenha um apoio pedagógico escolar, sendo auxiliado com currículo escolar e maneiras de desenvolver o trabalho. É nesse processo, também, que se realiza a troca de informações e avaliação do desenvolvimento do educando. Com essa relação mútua, entre pedagogo escolar e hospitalar, haverá maior acompanhamento do processo educativo e clínico, deixando-a mais segura para seu retorno no ambiente escolar. É importante a observação no sentido que a fase da escolaridade, no hospital, representa uma situação emergencial e transitória. Necessita de um preparo quanto ao seu retorno à normalidade, no sentido que haja uma garantia de continuidade tanto da identidade social do educando quanto de seu processo de aprendizado (PARANÁ, 2010).

E neste percurso, é o que justifica a necessidade de, durante a fase de hospitalização, haver um permanente estímulo às relações com a escola de origem, por meio de intercâmbio de informações e de manutenção de interesses. Com pertinência ao hospital, as relações apresentam, muitas vezes, um desafio, no sentido desbloqueador e promotor do progresso de todos os envolvidos, ou seja, aproximando os familiares, a escola e o pedagogo hospitalar para inspirar segurança, e que dos educandos tenham condições para progredir de forma mais harmoniosa, sem deixar de crescer e evoluir nesta fase difícil de sua vida (PARANÁ, 2010). É importante promover além de bem-estar ao educando, um processo de interação entre os familiares e a equipe técnica do hospital, auxiliando no processo de reabilitação, cura e desenvolvimento humano.

\section{Considerações finais}

A Educação torna-se cada vez mais relevante na vida de todas as pessoas e, diante disso, percebe-se a grande necessidade do desenvolvimento de práticas educativas nos mais diversos espaços, pois o ato de ensinar não 
acontece somente no interior das escolas. O hospital é mais um dos ambientes onde a educação pode acontecer, espaço este que o pedagogo ou professor podem atuar como colaboradores do desenvolvimento do processo educativo para dar continuidade à escolarização de crianças e adolescentes. O objetivo destes atendimentos pedagógicos é estimular a capacidade de aprendizagem, o trabalho com os laços afetivos e interação com o outro nos processos de ensino e aprendizagem.

Evidencia-se que o ambiente hospitalar pode ser um espaço propício para a educação e novos aprendizados. É um local que tem se mostrado um ambiente de ampla atuação do pedagogo ou professor hospitalar e que faça acompanhamento pedagógico-educacional de crianças e adolescentes em tratamento de saúde. Este processo de acompanhamento é complexo, uma vez que o pedagogo ou professor precisam lidar com o educando assistido que sofreu alterações emocionais e psicológicas, devido a situação hospitalar, no decorrer do processo. Portanto as práticas pedagógicas no hospital exigem dos profissionais da educação envolvidos maior flexibilidade, dedicação, planejamento para cada especificidade, de acordo com o indivíduo e suas dificuldades.

A Pedagogia Hospitalar ainda é um tema que precisa ser discutido mais profundamente em relação à forma que se dá a articulação da equipe multidisciplinar hospitalar com a escola de origem do educando atendido. Uma vez que esta articulação visa garantir a continuidade do desenvolvimento cognitivo e educacional dos pacientes durante o período de hospitalização. Ademais, possibilita o acompanhamento curricular dos conteúdos que já foram e os que ainda não foram abordados na escola de origem, a manutenção do vínculo escolar, fortalece o trabalho do educador da escola quando o educando retorna a sala de aula. E ainda, este trabalho em conjunto, favorece e ajuda o retorno ao ensino regular porque em muitos casos, por terem ficado muito tempo ausentes, preferem deixar estes espaços ou sentem dificuldade de se sentirem pertencentes novamente. 


\section{Referências}

BARROS, Alessandra Santana Soares. Contribuições da educação profissional em saúde à formação para o trabalho em classes hospitalares. Cadernos CEDES, v.27, n.73, dez., 2007. ISSN 0101-3262.

BRASIL. Constituição (1988). Constituição: República Federativa do Brasil. Brasília, Distrito Federal: Senado Federal, 1988.

BRASIL. Lei Federal $n^{\circ}$ 9394/96, de 20 de dezembro de 1996. Institui as Diretrizes e Bases da Educação Nacional. Diário Oficial, Brasília, Distrito Federal, 1996.

BRASIL. Conselho Nacional de Educação. Resolução CNE/CP n ${ }^{\circ} 01$, de 15 de maio de 2006. Brasília, Distrito Federal: Senado Federal, 2006.

BRASIL. Lei Federal $n^{\circ}$ 8069, de 13 de julho de 1990. Institui o Estatuto da Criança e do Adolescente e dá outras providências. Diário Oficial da União, Brasília, Distrito Federal, 1990/2013.

CARDOSO, Clodoaldo Meneguello. Uma visão holística de educação. São Paulo: Summus, 1995.

CECCIM, Ricardo Burg. Classe Hospitalar: encontros de Educação e da Saúde no Ambiente Hospitalar. Revista Pátio, Porto Alegre, v. 03, n. 10, ago/out., 1999.

CECCIM, Ricardo Burg; FONSECA, Eneida Simões da. Atendimento pedagógico-educacional hospitalar: promoção do desenvolvimento psíquico e cognitivo da criança hospitalizada. Temas sobre Desenvolvimento, v.8, n.44, 1999.

DUTRA, Vanessa Aparecida. História da Pedagogia Hospitalar no Brasil. Trabalho de Conclusão de Curso (Graduação em Pedagogia) - Universidade Estadual de Londrina, Londrina, 2009.

FONSECA, Eneida Simões da. Atendimento escolar no ambiente hospitalar. 1 ed. São Paulo: Memnon Edições Científicas, 2003.

FONTES, Rejane. A escuta pedagógica à criança hospitalizada: discutindo o papel da educação no hospital. Revista Brasileira de Educação, n. 29, ago., 2005, ISSN 1413-2478.

LOVISOLO, Elena. Larousse Cultural: dicionário de língua portuguesa. São Paulo: Nova Cultural, 1992. 
MATOS, Elizete Lúcia Moreira. A hospitalização escolarizada e a formação do professor para atuar em contexto hospitalar. In: Secretaria de Estado da Educação. Superintendência de Educação. Diretoria de Políticas e Programas Educacionais. Núcleo de Apoio ao Sareh. Curitiba: SEED/PR., 2010. - 140 p.

MATOS, Elizete Lúcia Moreira. MUGIATTI, Margarida Maria Teixeira de Freitas. Pedagogia Hospitalar: A humanização integrando educação e saúde. 4 ed.Petrópolis, Rio de Janeiro: Vozes, 2009.

MATOS, Elizete Lúcia Moreira. O desafio do professor universitário na formação do Pedagogo para atuação na educação hospitalar. 157f. Dissertação (Mestrado em Educação), Pontifícia Universidade Católica do Paraná, Curitiba, 1998.

PARANÁ. Secretaria de Estado da Educação. Superintendência de Educação. Diretoria de Políticas e Programas Educacionais. Núcleo de Apoio ao Sareh. Serviço de Atendimento à Rede de Escolarização Hospitalar (Sareh) - Curitiba: Seed-PR., 2010. 140 p.

PARREIRA, Lúcia Aparecida; JOSÉ FILHO, Mário. A Educação não formal: desafios de uma prática pedagógica. Revista Serviço Social e Realidade, v.19, n.1. São Paulo, 2010.

REIS, Viviane de Souza; COSTA, Veronica Bernarda. Pedagogia Hospitalar: um novo campo de atuação do professor Pedagogo. Revista EDUTEC, v. 01, n. 15, p. 1-6, 2015.

RIBEIRO, Márden de Pádua. Por uma pedagogia crítica. Ensino em ReVista. Uberlândia, MG. v. 23, n. 2, p. 522-547, 2016.

SANTOS, Maria Cecília Huzmann. A atuação do Pedagogo na escolarização hospitalar e domiciliar. X Congresso Nacional de Educação (EDUCERE). Pontifícia Universidade Católica do Paraná, Curitiba, 2011.

SILVA, Aline Fabiana da; CARDOSO, Cristiane Aparecida; SANTOS, Mauro Augusto dos. O Trabalho do Pedagogo no Ambiente Hospitalar. Revista Brasileira de Educação e Cultura, v. 01, n. 04, jul./dez., 2012.

TAVARES, Bruna Feijó. A Pedagogia no espaço hospitalar: contribuições pedagógicas a um ambiente de renovação e aprendizagem. Trabalho de Conclusão de Curso (Curso de Pedagogia). Centro Universitário Municipal de São José - USJ, São José, 2011. 